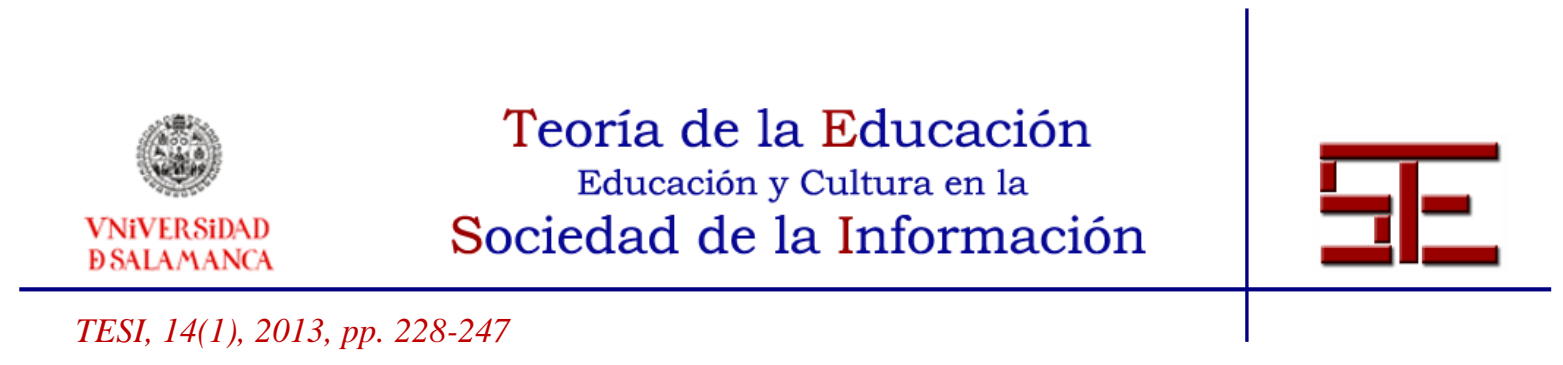

\title{
LA PREPARACIÓN DE COMUNICADORES RESONANTES. DE LAS REDES NEURONALES A LA SOCIEDAD RED
}

Resumen: La gestión de los medios de comunicación ha dejado de ser dominio exclusivo de empresas y profesionales especializados. Los nuevos proyectos docentes también deben servir para el empoderamiento de los usuarios en el ejercicio de la nueva ciudadanía digital.

Junto a la preparación técnica indispensable para moverse en un mundo interconectado, es indispensable su alfabetización emocional para querer participar de manera efectiva en esta comunidad aumentada. Además de acercarles a las técnicas de creación audiovisual, este proyecto busca reprogramar la relación del alumnado con una situación típicamente estresante.

Nuestra propuesta de práctica expandida permite a los sujetos reconocer y activar a voluntad su biología comunicativa. De esta manera, los usuarios pueden convertirse en actores de las redes sociales, aumentando la pluralidad y enriqueciendo los flujos comunicativos globales.

Palabras clave: Comunicadores resonantes; experiencia de flujo; visualización; aprensión comunicativa; sociedad red.

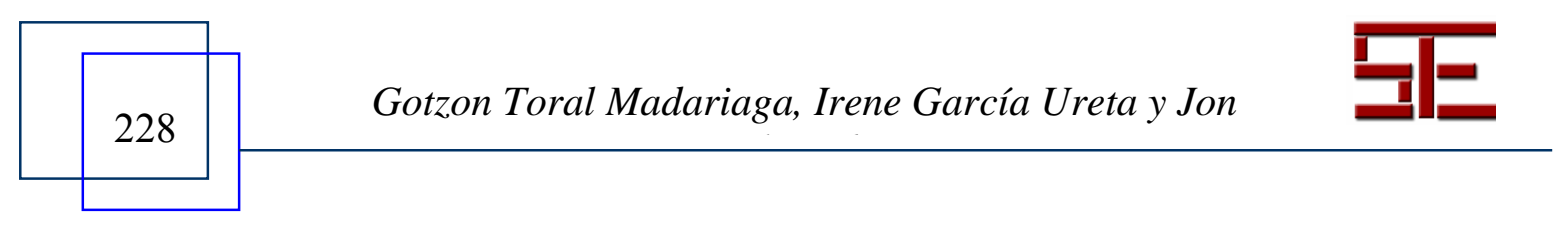




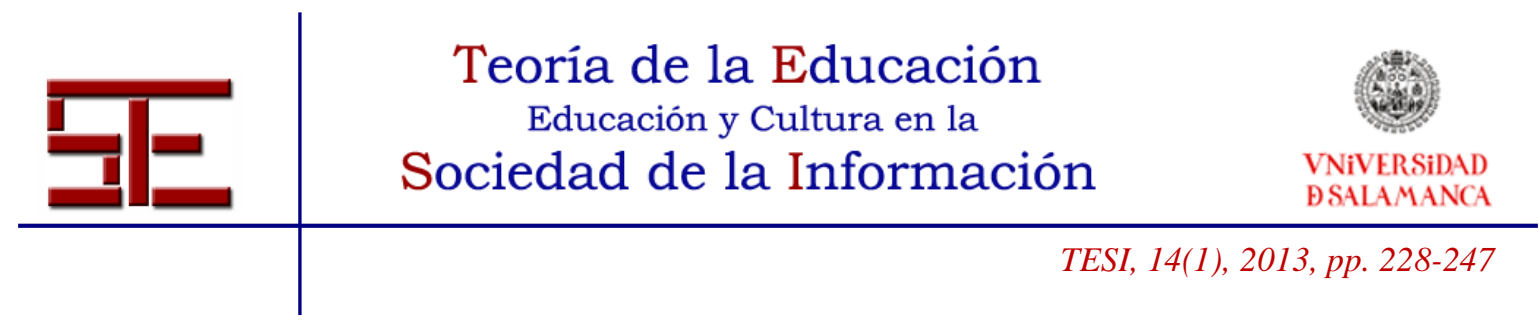

\section{TRAINING RESONANT COMMUNICATORS. FROM RAINING RESONANT COMMUNICATORS. FROM NEURAL NETWORKS TO NETWORK SOCIETY}

Abstract: Media control is no longer exclusively in the hands of professional broadcasters. New educational projects must empower users so that they can exercise their digital citizenship.

As well as acquiring essential technical skills to move in an interconnected world, emotional literacy is also indispensable for people to desire to take part effectively in this augmented community. So, besides teaching audiovisual technology, this project seeks to re-program the relationship that students develop with a situation that is typically stressful.

We propose an expanded practice that enables students to recognize and voluntarily activate their communication biology. This way, users can become actors in new communication networks, and global communication flow will be more plural and richer.

Keywords: Resonant communicators; flow experience; visualization; communication apprehension; network society.

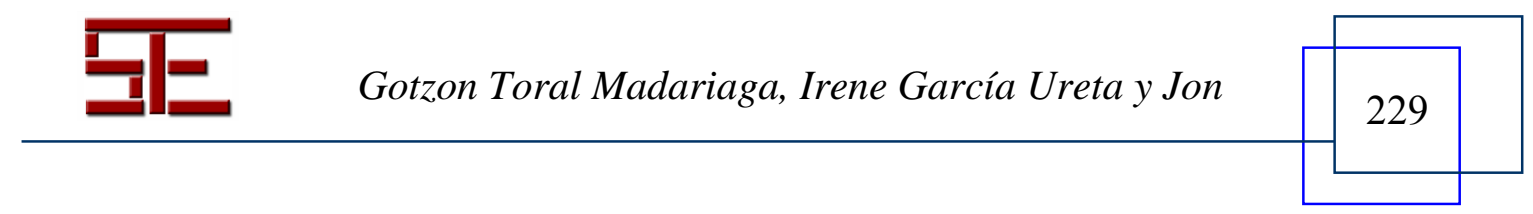




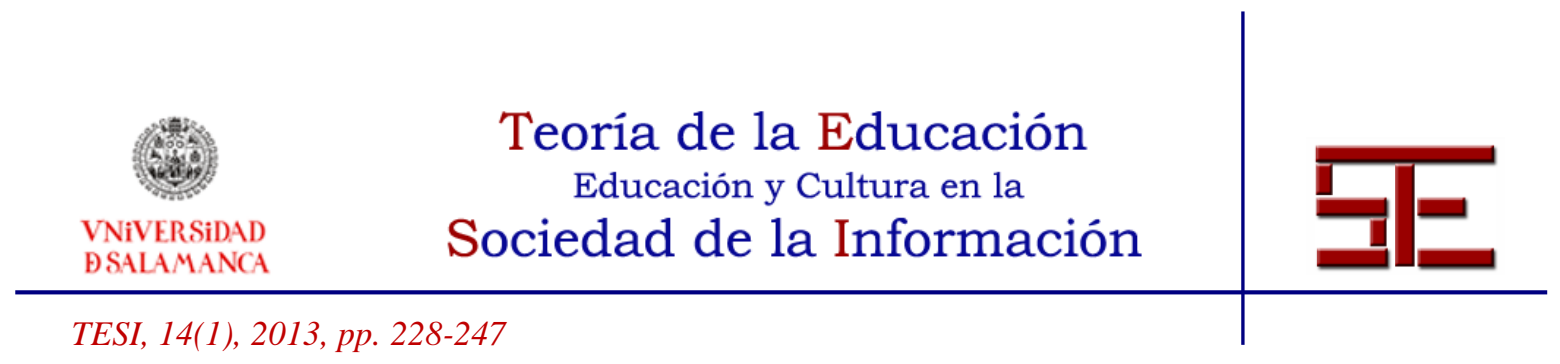

\section{LA PREPARACIÓN DE COMUNICADORES RESONANTES. DE LAS REDES NEURONALES A LA SOCIEDAD RED}

Fecha de recepción: 25/02/2011; fecha de aceptación: 01/12/2012; fecha de publicación: 28/02/2013

Gotzon Toral Madariaga

joseangel.toral@ehu.es

UPV-EHU

Irene García Ureta

cypgauri@1g.ehu.es

UPV-EHU

Jon Murelaja Ibarra

jon.murelaga@ehu.es

UPV-EHU

\section{1. - Introducción}

Hace tiempo que el estatus y funciones de los comunicadores audiovisuales se alejaron del canon formal que inspiraba la mayoría de los proyectos docentes de Locución. La formación académica se desconectó del nuevo modelo de proximidad emocional generalizado en la comunicación pública y, en consecuencia, de las necesidades del alumnado.

Tan es así, que el principal obstáculo para el aprendizaje percibido por sus protagonistas -un miedo escénico desproporcionado en su exposición pública- se contemplaba como una experiencia pasajera e inevitable. Sin embargo, la competencia profesional no deja de aumentar esta presión asociada a una situación típica de evaluación social como es hablar en público y ganarse su confianza. Este déficit en el aprendizaje puede convertirse en amenaza permanente para unos profesionales sometidos al dictado de los índices de audiencia.

La reforma para la creación de un Espacio Europeo de Educación Superior ofrece la oportunidad de poner al día unos planes docentes más atentos al discurso vertical de los grandes medios de comunicación que a la interactividad de la Sociedad Red (Castells, 2009). Esta revisión debiera reparar ausencias tan clamorosas como la atención a la inteligencia relacional del alumnado de Ciencias de la Comunicación, verdadero punto

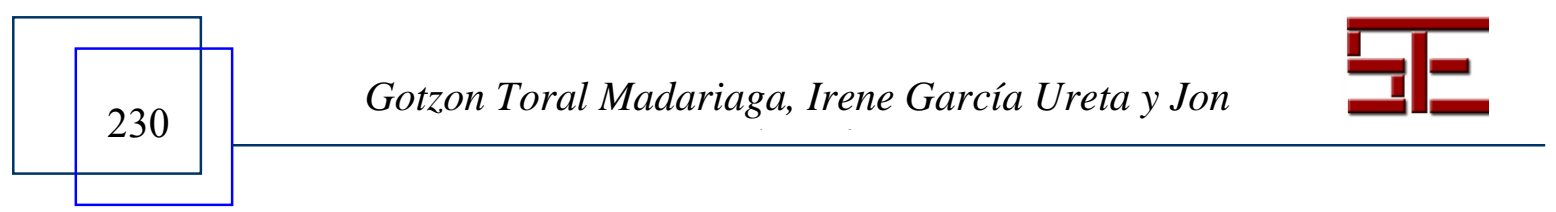




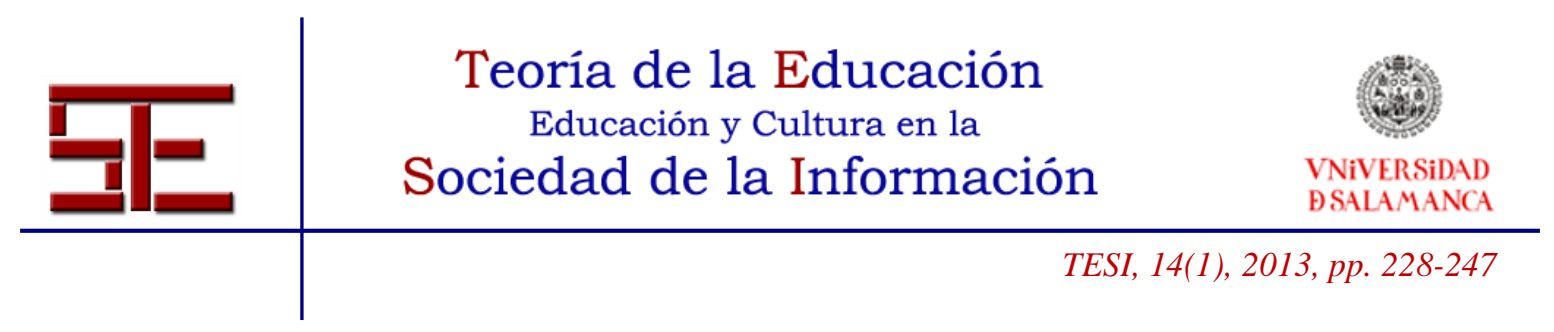

ciego de una magnitud comparable al supuesto de que los estudios de imagen siguieran anclados en el cine mudo.

La multiplicación de medios y posibilidades de interactuar con todo el mundo, y sus implicaciones personales, sociales y económicas, alimentan un movimiento de expansión permanente del universo de la comunicación humana. Prepararse para esta conectividad total de medios y usuarios en Internet implica replantear los mismos fundamentos de las ciencias de la comunicación. Es de creer que este seísmo que tiene su centro de gravedad en el dominio de la comunicación pone en entredicho tanto lo que se enseña, como los medios y la misma pedagogía de aprendizaje.

Las transformaciones no se agotan en la negociación de unos perfiles profesionales cada vez más borrosos por la convergencia digital. Los medios de producción y distribución de mensajes en red tienden a ser tan accesibles como los aparatos receptores, favoreciendo un nuevo contrato en la relación entre la industria y los usuarios. Las empresas y los profesionales han perdido el monopolio en la producción y distribución informativa, en beneficio de redes de usuarios con las que conviven en un nuevo ecosistema mediático. Los proyectos docentes deben servir también para el empoderamiento de estos usuarios que quieren y pueden ejercer su nueva ciudadanía digital.

Interactuar en este entorno global pone a prueba -junto a las competencias técnicas indispensables para moverse en un ambiente multimedia- la inteligencia social de los individuos. Afortunadamente, los últimos descubrimientos de las neurociencias confirman que el ser humano está programado para conectar con los demás. El descubrimiento de las neuronas espejo demuestra que nuestra biología está equipada para la relación social, a través de una vía rápida emocional que discurre al margen de la actuación consciente del sujeto.

El pleno uso de estas capacidades empáticas del individuo, y su extensión instantánea a través de las redes, permitiría utilizar todo este potencial interactivo sin restricciones, desde el espacio interpersonal y local al ámbito global. Sin embargo, la brecha tecnológica abierta en nuestras sociedades, así como la falta de práctica social por una percepción amenazante de la interacción con los demás, interfieren en el desarrollo de esta banda ancha de la comunicación humana.

Nuestro proyecto docente persigue empoderar a usuarios y profesionales como nodos inteligentes de esta Sociedad Red, capaces de generar una mayor pluralidad en los flujos

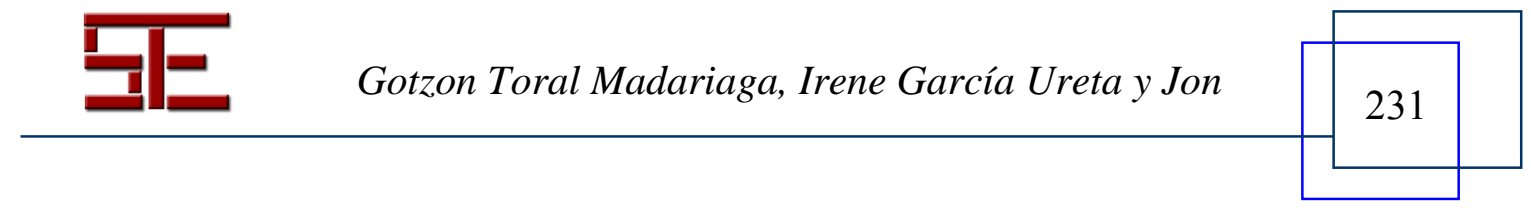




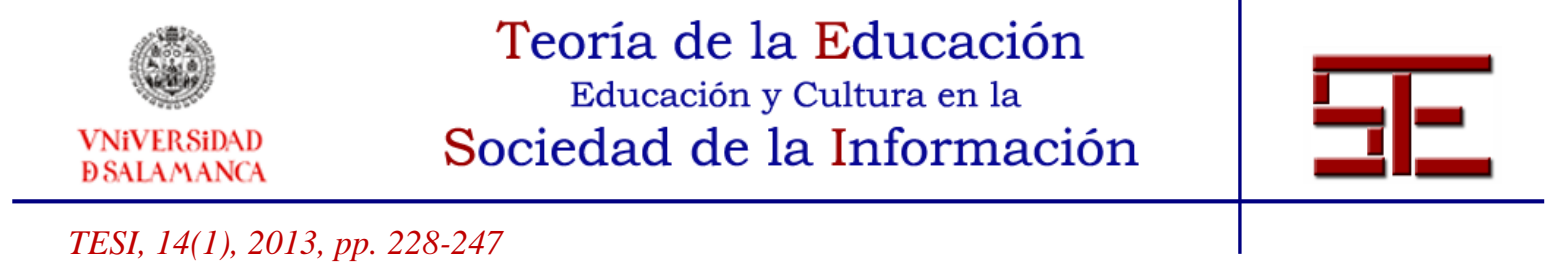

comunicativos globales. Se pretende reprogramar la relación de los sujetos con una situación estresante, a través de su exposición expandida y positiva a la comunicación. Además de las prácticas de grabación, se realizan ejercicios de relajación respiratoria, modelización y visualización, de probada eficacia en otras disciplinas tan exigentes como el deporte de competición. Esta intensa práctica, acompañada de un refuerzo positivo, actúa de catalizador de la biología comunicativa del sujeto, al liberar su sistema empático de los hábitos aprendidos que le llevaban a reducir y evitar la interacción con los otros. Nuestro plan docente adopta el modelo de flujo (Csikszentmihalyi, 1990) para el rendimiento óptimo en cualquier actividad, mediante el equilibrio entre exigencias del reto y destrezas del sujeto. En esta investigación hemos supervisado el progreso de un grupo de estudiantes de Locución en radio y televisión, para contrastar la eficacia de esta nueva estrategia formativa. De manera específica queríamos verificar si la percepción de claridad en la visualización previa a una grabación es un predictor eficaz de la calidad en su práctica posterior.

\subsection{Exposición versus aprensión a la comunicación}

Hablar y exponerse en público es una actividad que muchas personas experimentan como amenaza, lo que genera altos niveles de ansiedad. Se estima que hablar en público es el temor social más extendido, que afecta casi al 75\% de la población (Bados, 2008; Furmark; Tilfors; Everz, 1999; McCroskey, 2009).

Esta aprensión comunicativa no es un susto que se mete en el cuerpo y se va como ha venido, ni se reduce a las etapas de iniciación, sino que afecta también a profesionales experimentados en otros ámbitos, como la docencia o la interpretación escénica (Thomas, 2005). La percepción exagerada de una situación de evaluación social está muy condicionada por el estado emocional del individuo y el contexto de la prueba. En este sentido, la disputa de los medios por la atención menguante del público es una fuente de alarma permanente que los profesionales deben sobrellevar.

Existe, por tanto, una relación de vasos comunicantes entre la percepción de la situación por parte del individuo y su competencia comunicativa. McCroskey (1984a, b) definió el concepto de aprensión comunicativa como el nivel de miedo o ansiedad que un individuo siente asociado a la comunicación real o anticipada con otra persona o personas. La falta de habilidades comunicativas o de preparación producen una ansiedad que McCroskey (1984a) denominó racional. Sin embargo, aun disponiendo de tales habilidades, este autor

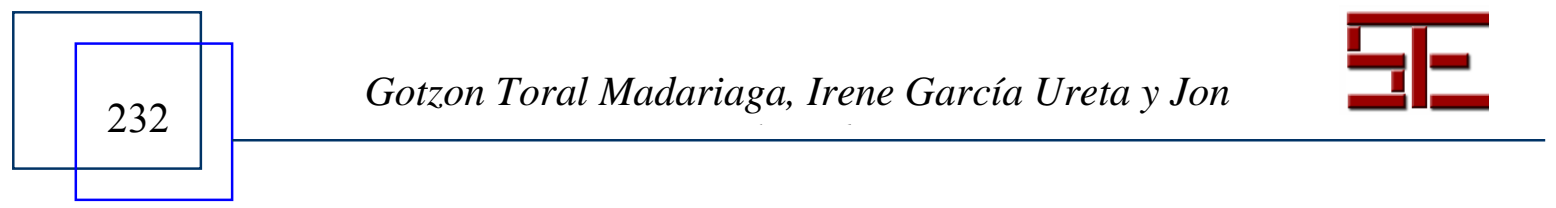




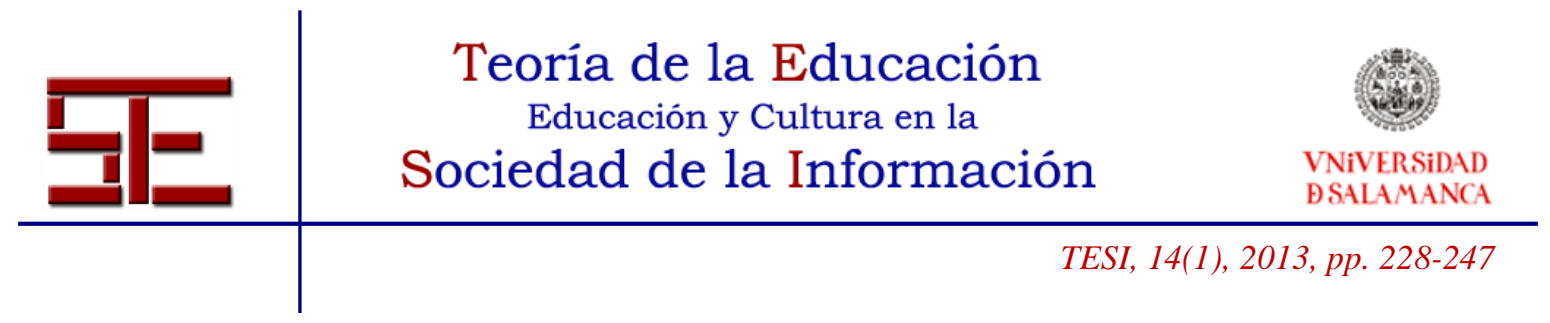

detectó un elevado nivel de ansiedad no racional, al tratarse de una situación típicamente estresante de exposición a la evaluación de los demás.

En el esquema siguiente se puede ver la relación entre las destrezas desarrolladas por el comunicador en su exposición habitual a una tarea - eje vertical-y su percepción de mayor o menor autoconfianza en sus capacidades -eje horizontal-. Además de su competencia, la confianza del sujeto resulta determinante de la relación que propone al público y, en consecuencia, de la respuesta previsible en un circuito-espejo cuyo funcionamiento tiende a la resonancia.

\section{Exposición sí}

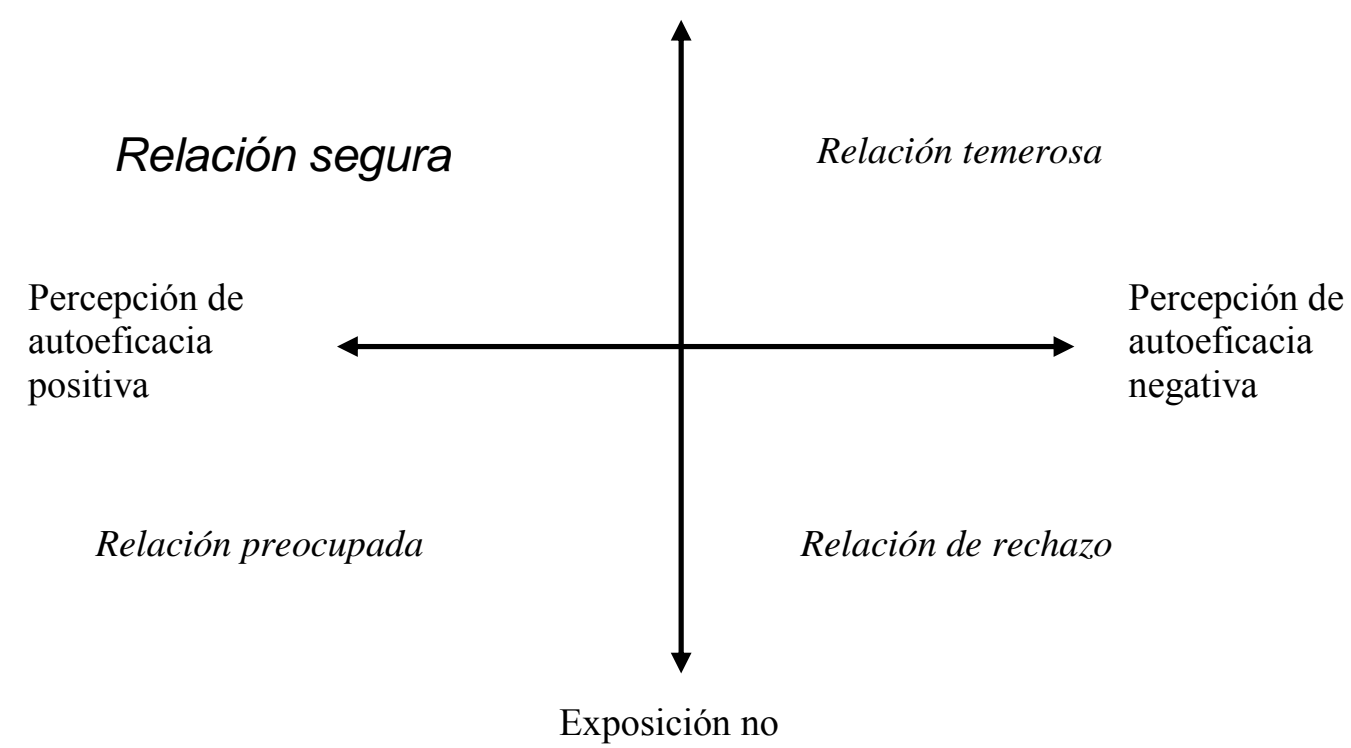

Fig. 1. Estilos de Comunicación en función de la experiencia y autoconfianza

Aprender a gestionar su comunicación en situaciones de cierta tensión y reforzar el estilo personal del comunicador son, por tanto, dos aspectos de un mismo reto: la alfabetización emocional de los comunicadores que les permita reconocer su biología comunicativa y desarrollar su estilo personal en el nuevo escenario de alta exigencia de rendimiento.

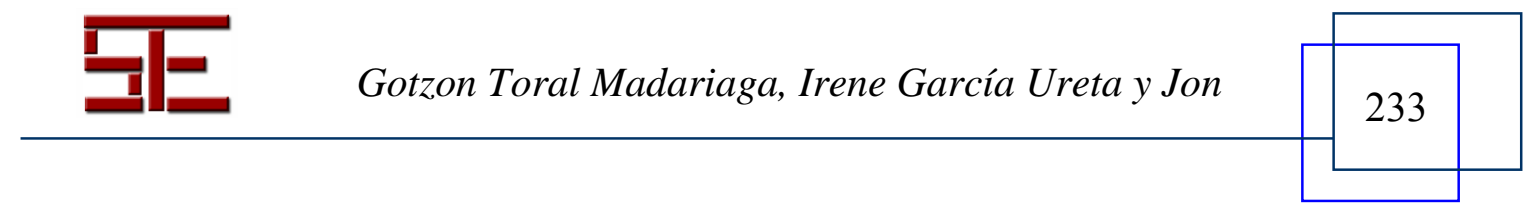




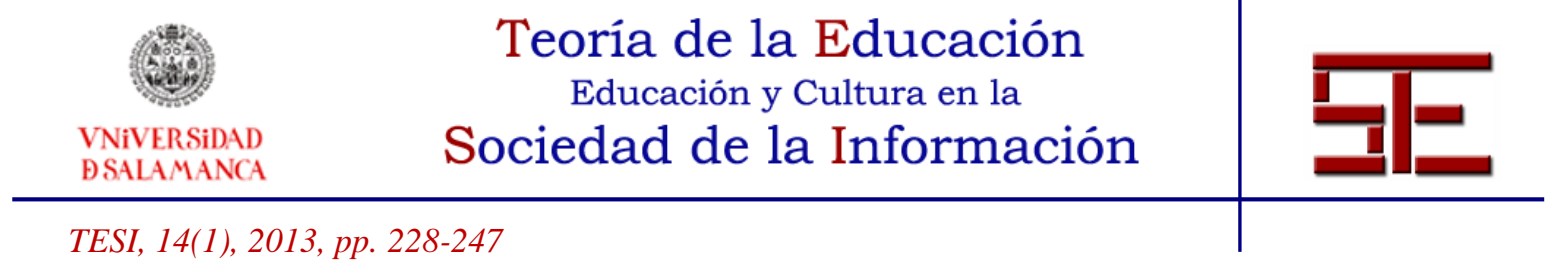

La estrategia de formación que hemos ensayado atiende a las necesidades prioritarias del alumnado y a las premisas elementales que ayudan a reprogramar la mente del sujeto ante una situación estresante: cómo dejar de huir, como relacionarse mejor y cómo pensar de otra manera (Legerón,1997, 167). En lugar de evitarla, magnificando la sensación de amenaza, se propone una exposición intensa, equilibrada y expandida que familiarice al sujeto con la situación temida, para disolver la aprensión real e imaginada.

Esta puesta a punto de la biología social del individuo le permite aprovechar los mejores recursos que la evolución humana ha desarrollado con el fin de poder conectar y compartir con los otros.

Como explica la Escuela de Palo Alto, es imposible no comunicar: comunicamos con todo el cuerpo y en todo momento, aun sin saberlo (Watzlawizc; Beavin; Jackson: 1981). En efecto, la neurociencia social demuestra que la evolución ha programado al ser humano para conectar automáticamente con los demás. Las neuronas espejo favorecen este deporte de relación social, al disponernos constantemente a la imitación en cualquier interacción. Nuestro sistema empático funciona como una caja de resonancia que vibra por simpatía al entrar en contacto con otras personas. Esta especie de piloto automático toma nota de los movimientos que los demás están a punto de hacer, así como de sus sentimientos, moviéndonos a imitar sus gestos $\mathrm{y}$, en consecuencia, a sentir lo mismo. (Iacoboni: 2009).

Giacomo Rizzolatti explica que estas pautas automáticas nos permiten entender a los demás de manera inconsciente, al sentir lo mismo que nuestros interlocutores. (Rizzolatti; Craighero, 2004). La consecuencia de esta actividad replicante de nuestro sistema empático es una remodelación constante en los circuitos neuronales de quienes interactúan. La evidencia de que toda interacción moldea, incluso de forma inadvertida, el cerebro de los participantes, tiene implicaciones de indudable interés en nuestro ámbito. Esta neuroplasticidad cerebral demuestra que las experiencias repetidas son la herramienta más eficaz del ser humano para aprender nuevos procedimientos. El efecto bumerán explica la eficacia del aprendizaje por imitación: además de hacer directamente, ver e imaginar modelos en acción sirve de guía y ejemplo eficaz para adquirir nuevos hábitos.

El conocimiento de estas pautas automáticas que moldean nuestro cerebro pone en evidencia la responsabilidad social de las empresas de comunicación en la difusión de valores y modelos cuya resonancia en las audiencias resulta tan determinante. Al mismo

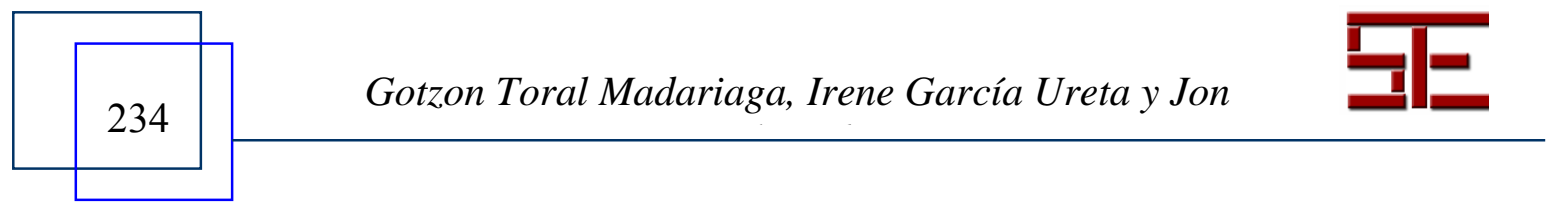




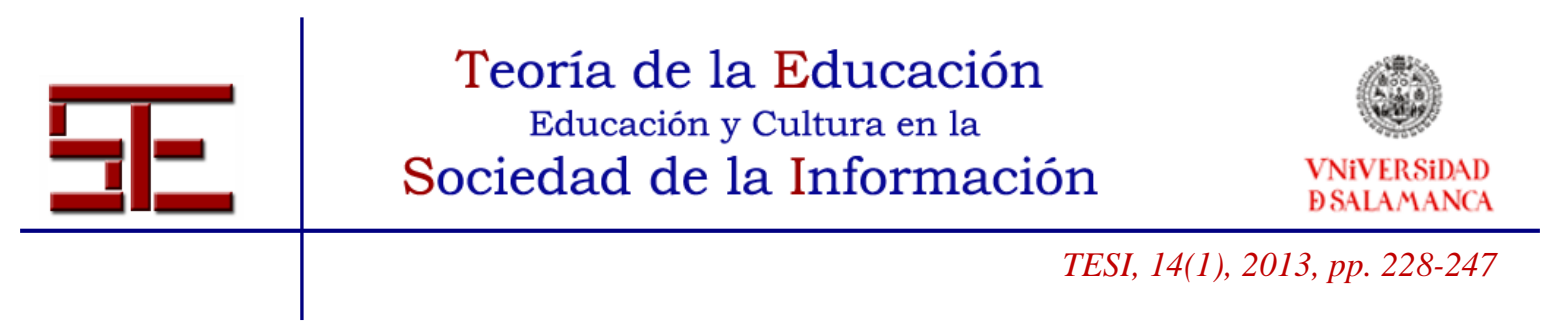

tiempo, explica la exhibición entusiasta de las emociones positivas de los comunicadores para inducir una respuesta favorable en las audiencias (Goleman; Boyarzis, 2002; Petrides, 2011). Como docentes, debemos ayudar a despejar los obstáculos que interrumpen esta autopista de la comunicación humana, advirtiendo que se trata de una tecnología de doble uso: igual que favorece el contacto, también nos pone a merced de los demás (Goleman, D: 2011).

\section{2. - Práctica expandida y visualización guiada}

Para superar los temores asociados a la exposición a los otros, esta preparación de comunicadores resonantes se basa en la activación de los recursos naturales del alumnado mediante la práctica de un variado repertorio de procedimientos de interacción social, junto con un refuerzo positivo de su motivación a compartir con los demás. Además de las prácticas habituales en Laboratorio, la observación de modelos -práctica de modelización- así como la visualización guiada -anticipación mental positivacontribuyen a disolver la aprensión racional e imaginaria, familiarizándoles con la tarea. En general, los programas dirigidos a la reducción de la ansiedad comunicativa no racional pueden clasificarse en intervenciones de orientación cognitiva e intervenciones de orientación afectiva (Ayres, 1997). Las intervenciones cognitivas se centran en los pensamientos negativos acerca de una situación que provocan ansiedad, de manera que si se tratan esos pensamientos, la ansiedad puede reducirse. Estas intervenciones incluyen la reestructuración cognitiva, la terapia de modificación de la orientación cognitiva y la visualización (Schmidt, 2006). Mediante la reestructuración cognitiva, se enseña a las personas a identificar sus pensamientos negativos, diseñar o crear frases positivas alternativas y usarlas para contrarrestar estos pensamientos negativos. La terapia de modificación de la orientación cognitiva trata de instruir a los sujetos para que, en lugar de estar pendientes de la mirada aprobatoria de los demás, piensen en la oportunidad de compartir ideas con una audiencia interesada en lo que dice.

Los procedimientos de visualización y modelización completan este repertorio de herramientas para familiarizar al sujeto con la tarea. El funcionamiento resonante del sistema de neuronas espejo explica la capacidad que tienen las técnicas de observación de modelos -ampliamente utilizadas en el campo de la psicología- de moldear el cerebro humano para automatizar nuevos hábitos. En esta investigación, queríamos contrastar la validez de esta práctica expandida $\mathrm{y}$, de manera específica, la eficacia de un entrenamiento en técnicas de visualización que han demostrado su utilidad en otros ámbitos profesionales como el deporte de alto rendimiento.

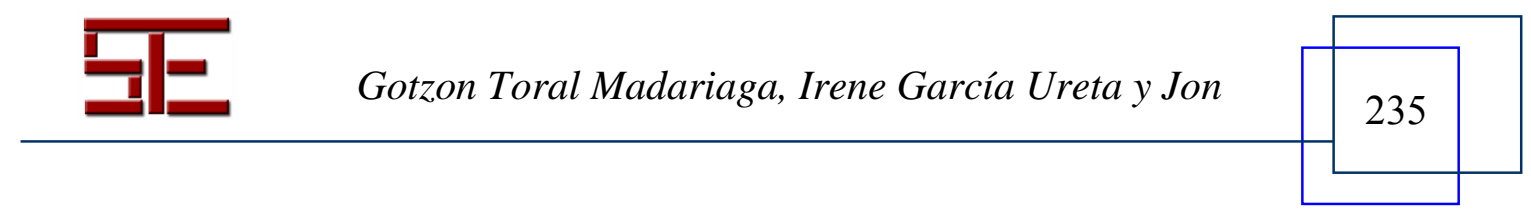




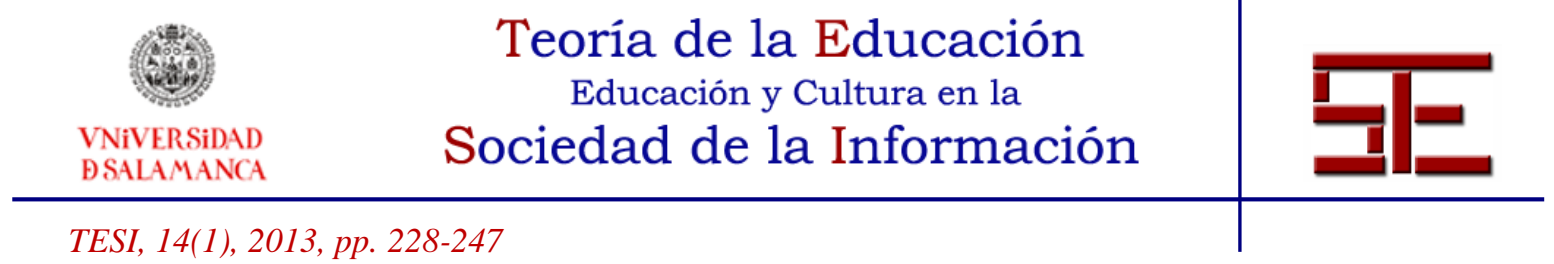

La visualización positiva interrumpe las imágenes negativas que acuden a la mente de un individuo ansioso, al punto de desestabilizarlo. En este caso, se utiliza la imaginación del sujeto para crear una representación mental que anticipe la vivencia de un escenario más favorable. Esta práctica permite al sujeto exponerse en cualquier momento a una simulación de la tarea, adquiriendo así los automatismos necesarios para su mejor desempeño, dado que el cerebro responde de manera similar a como lo hace en una práctica real. Hall, Mack, Paivio y Hausenblas (1998) han descrito que la visualización puede utilizarse con una función cognitiva y/o motivadora. Dentro de la función cognitiva se incluye la recreación de habilidades concretas, por ejemplo, imaginarse manteniendo una determinada postura o expresión facial. La función motivadora incluye recordarse objetivos, por ejemplo, imaginarse felicitado por los demás al final de la actuación, ayudar a controlar el nivel de activación, permaneciendo más sereno, y fomentar la sensación de focalización de la atención, para alcanzar una concentración plena en la tarea.

Las intervenciones de orientación afectiva abordan los sentimientos o emociones negativas asociadas a la situación de comunicación e incluyen reacciones fisiológicas como el aumento de la tasa cardiaca, del ritmo respiratorio o de la transpiración. El control del ritmo respiratorio se ha mostrado eficaz en la disminución de la frecuencia cardiaca y de los niveles de estrés y ansiedad (Gatchel y Proctor, 1976; Cea y Reyes, 2005).

\section{3. - Modelo de flujo: disfrute y efecto espejo en las audiencias}

Nuestra estrategia formativa intenta generar un efecto positivo directo sobre la percepción del individuo acerca de su auto eficacia. Bandura define la auto eficacia como las creencias del sujeto acerca de su capacidad para llevar a la práctica sus habilidades en una situación determinada (Bandura, 1997).

Igual que McCroskey (1984a) se refería a una evitación racional y no racional de las situaciones de comunicación, Bandura contempla las creencias del individuo en la insuficiencia de sus capacidades tanto si están objetivamente fundadas, como si son de naturaleza no racional. En ambos casos, su creencia en una capacidad insuficiente provoca ansiedad, mientras que una percepción de equilibrio entre competencias y exigencias favorece la máxima atención y, consecuentemente, la experiencia óptima.

Ya se ha dicho que en la preparación de los comunicadores coinciden percepciones potencialmente amenazantes para el individuo: una situación novedosa de evaluación típicamente estresante, agravada por la evaluación académica. La falta de una práctica

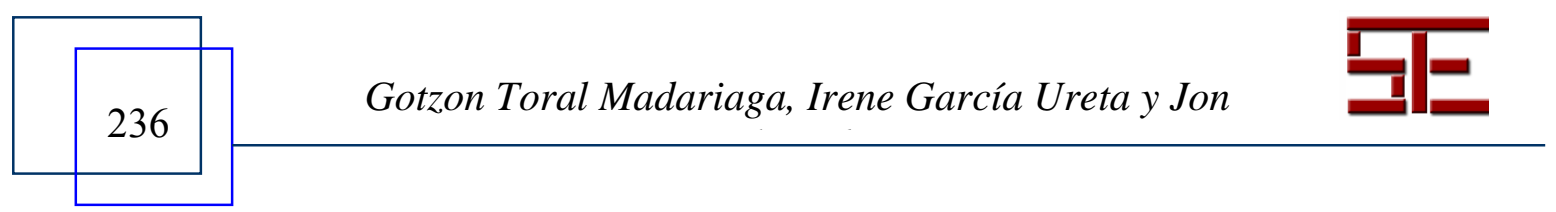




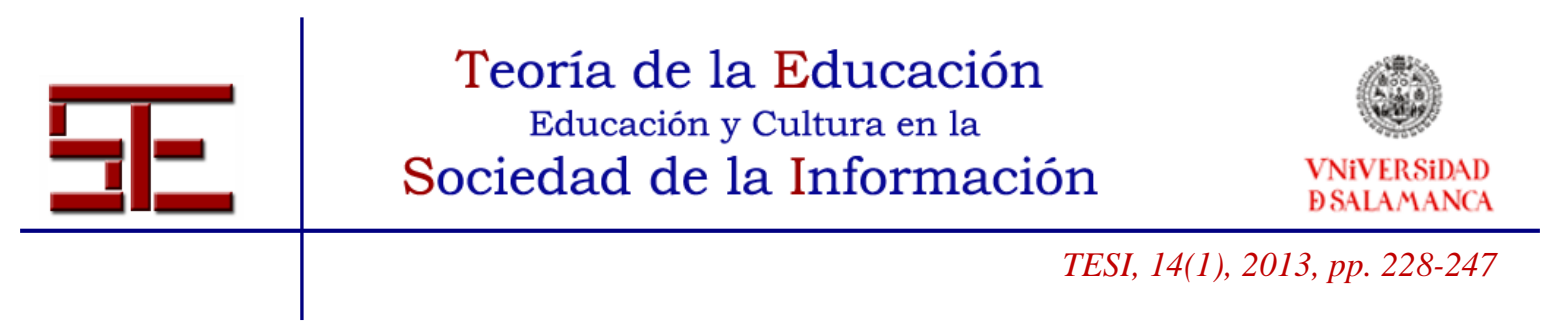

social previa, de ideas claras, destrezas comunicativas y habilidades para afrontar mejor las situaciones estresantes aumenta la dificultad de la prueba. El desafío que les aguarda en el ejercicio posterior de su oficio es mayor, por cuanto que su estabilidad profesional está sometida al dictado de las modas y los índices de audiencia.

Sabemos que una percepción exagerada de amenaza que sobrepasa sus capacidades genera un nivel de tensión que desborda al sujeto, le produce malestar, y le desconecta de la interacción comunicativa. En cambio, cuando sus pensamientos y emociones están alineados con lo que hace, su mensaje se refuerza y amplifica por resonancia entre sus interlocutores. Son tres, según Roshental y Degnan (1990), las características de una interacción de calidad: la máxima atención, la sensación de bienestar mutua y la coordinación no verbal. Esta sincronía de los sujetos que están en sintonía va acompañada de un placer de intensidad directamente proporcional al tamaño del grupo.

Mijalyi Csikszentmihalyi (1990) ha desarrollado el concepto de flujo que contempla las condiciones óptimas para el rendimiento en cualquier actividad humana y que inspira nuestra propuesta de formación -ver Figura II-. Esta experiencia de flujo es gratificante por sí misma y se describe en términos muy similares, independientemente del contexto profesional, en referencia a un estado tan deseable que el sujeto desea repetirlo. Alimentar esta fuente de alta motivación requiere elegir desafíos atractivos que pongan a prueba las habilidades propias, animando al sujeto a superarse. Cuando las habilidades y los retos son equilibrados, el individuo se siente atraído y disfruta concentrado en lo que hace. Para ello es imprescindible tener unas metas claras y un feed back adecuado que le advierte en todo momento de la buena marcha de la actividad, proporcionándole una sensación de dominio. Otra característica de esta vivencia es un sentido distorsionado del tiempo: el sujeto se olvida de lo demás y llega a perder conciencia de su propio ser en una experiencia autotélica, intrínsecamente placentera, en la que una clara visión de los objetivos pone a prueba al individuo y le permite expresar lo mejor de sí mismo.

La Figura II recoge la matriz de esta propuesta docente basada en el modelo de flujo adaptado a la comunicación audiovisual. El reconocimiento del estilo personal del alumno, y el desarrollo de los hábitos comunicativos más eficaces, se presentan en forma de reto equilibrado y atractivo que puede alcanzarse mediante una estrategia de exposición expandida.

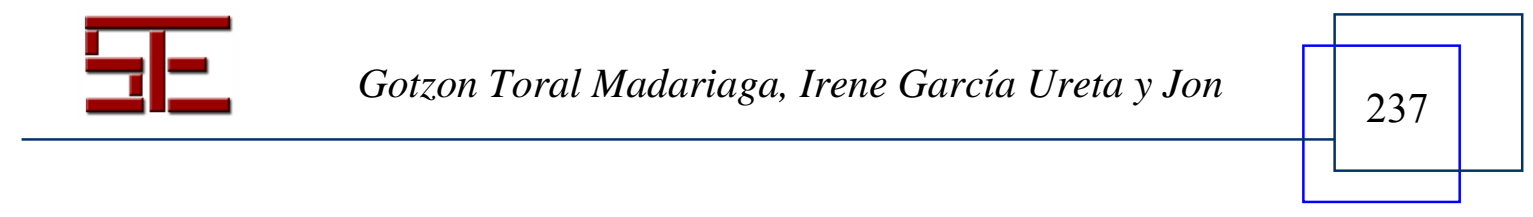



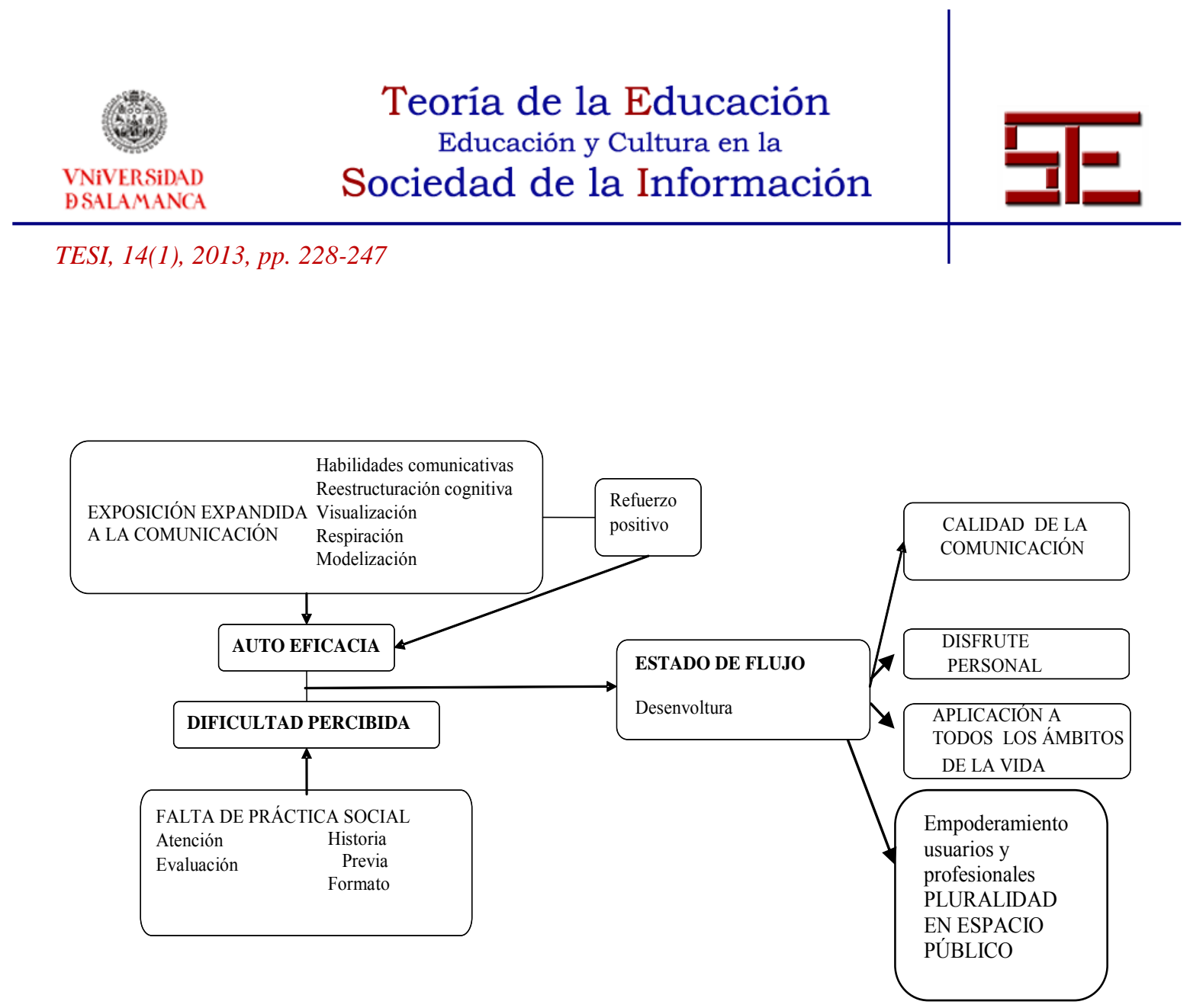

Figura II. Modelo de flujo adaptado a la preparación de comunicadores resonantes

La confianza que proporciona sentirse a la altura del desafío, permite al comunicador resonante mostrar su mejor versión en una vivencia muy gratificante de rendimiento óptimo. De esta manera puede superar la ansiedad provocada por un nivel de exigencia que le sobrepasaba, y le desconectaba de la actividad. Este disfrute de un reto atractivo le permite desenvolverse con fluidez en su relación con las audiencias, que tienden -por efecto espejo- a sincronizarse emocionalmente. Los públicos vibran por simpatía, experimentando las mismas sensaciones de bienestar que los comunicadores exhiben delante de las cámaras y micrófonos para agasajarles.

Ya Aristóteles intuyó los mecanismos de esta sintonía emocional que determinados sujetos son capaces de establecer con sus públicos. En su Retórica, describió el estilo patético como la capacidad expresiva que demuestran algunos comunicadores para sugerir estados de ánimo en el público, coherentes con la naturaleza del mensaje. De esta manera, su mensaje se amplifica en todos los sentidos, adquiriendo una resonancia extraordinaria: "Porque el alma del oyente deduce erróneamente que el orador habla con verdad, pues sobre todas las cosas los hombres reaccionan de esa manera [...] así que

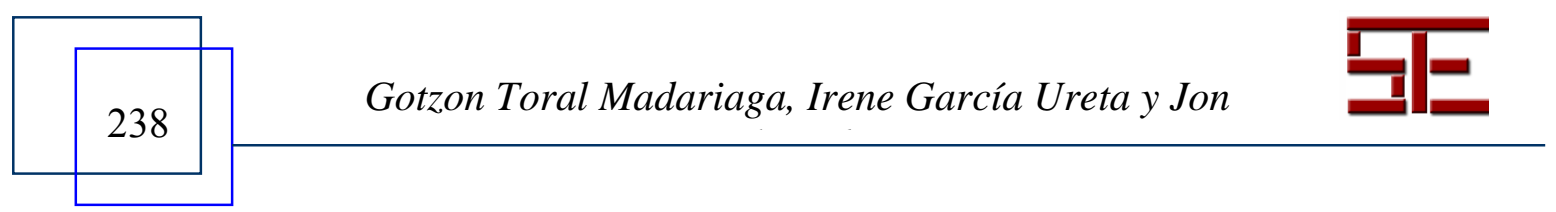




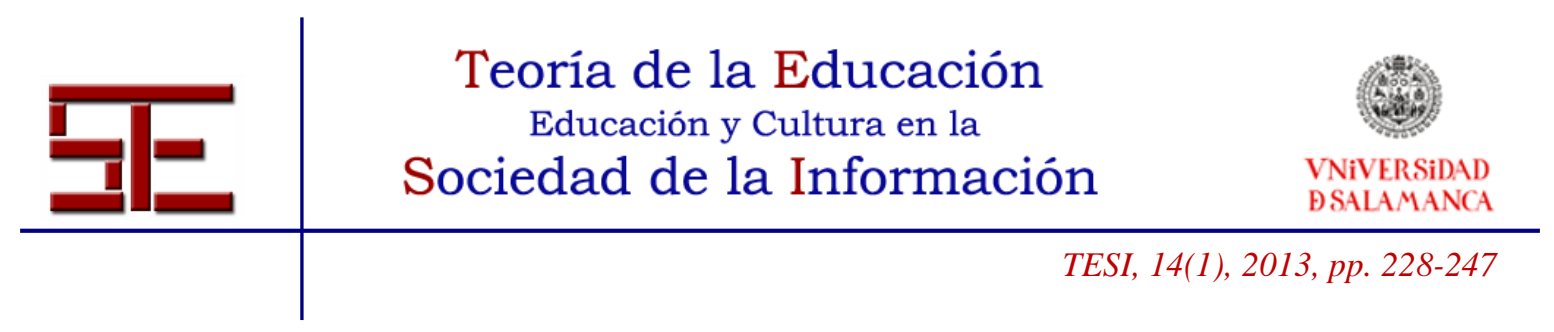

creen que todo es como él dice, y el oyente experimenta las mismas pasiones que el que habla con patetismo, aunque diga una nadería". (Aristóteles, 1971,192).

\section{2. - Procedimiento de la investigación}

El año 2009, este equipo de investigación combinó técnicas cuantitativas y prácticas cualitativas para monitorizar el aprendizaje de un grupo de 36 estudiantes de la asignatura optativa cuatrimestral de Locución y presentación en radio y televisión de la Facultad de Ciencias Sociales y de la Comunicación de la UPV-EHU. A todo el grupo se adiestró especialmente en el uso de técnicas de visualización.

Cada sesión semanal incluía dos horas de grabación en estudios, así como la revisión conjunta del material producido. A continuación, se desarrollaba una hora de clase en el aula, donde se explicaban conceptos de este modelo de flujo, se realizaban ejercicios de relajación respiratoria y se analizaban grabaciones de comunicadores elegidos por el alumnado como modelos de referencia.

En las sesiones de Laboratorio, la clase se dividió en dos subgrupos que grabaron diferentes formatos de locución con un grado de dificultad progresivo -noticia, presentación de musical, magacín, deporte y monólogo- alternando su práctica en radio y televisión. A lo largo de la semana tenían que aplicarse en la observación de comunicadores que admiraban, relacionados con el formato de la grabación que iban a realizar. Antes de cada una de las grabaciones, los alumnos debían realizar en los estudios un ritual de preparación que incluía también ejercicios de visualización, sustitución de pensamientos negativos y relajación respiratoria. Después de cada una de ellas, el alumnado respondía al cuestionario de visualización -elaboración propia a partir de la adaptación del cuestionario de visualización en el deporte (Hall, Mack, Paivio ; Hausenblas, 1998) - . La sesión en el Laboratorio finalizaba con un visionado de las grabaciones realizadas, analizando en grupo las mejoras y obstáculos percibidos.

Veintitrés de los participantes eran mujeres $(63,9 \%)$ y trece hombres $(36,1 \%)$, proporción que se corresponde con la presencia de ambos sexos en las licenciaturas de origen Comunicación Audiovisual y Publicidad y Relaciones Públicas-. El procedimiento de recogida de datos se integró en las rutinas de la asignatura, de manera que el alumnado participante realizaba autorregistros de las diferentes tareas. Todos los participantes dieron su consentimiento para que los datos fueran analizados dentro de este proyecto y respondieron el primer día de presentación de la asignatura a los siguientes cuestionarios:

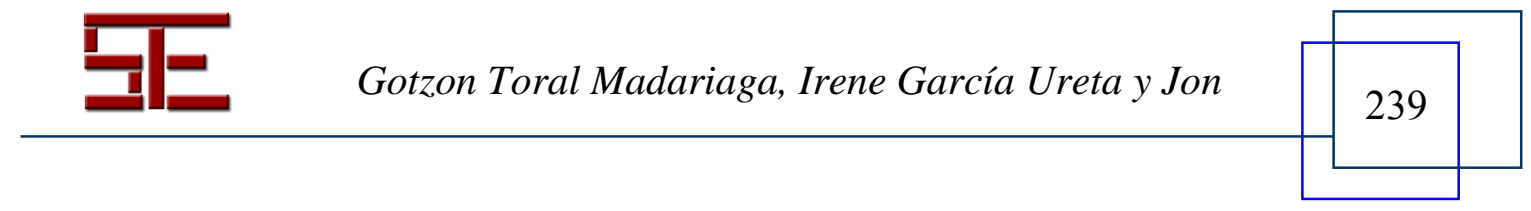




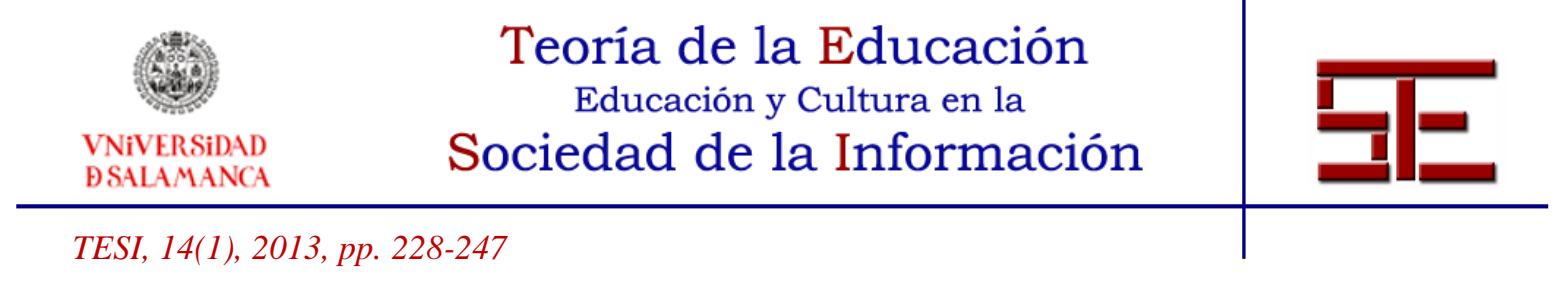

- Cuestionario de confianza para hablar en público. Versión reducida de la escala de Paul (1966), validada por Hook, Smith y Valentiner (2008).

- Cuestionario de confianza ante la Locución. Adaptado a partir del Informe Personal de Aprensión Comunicativa, subescala de Hablar ante un Público de McCroskey, 1997).

Posteriormente, el primer día de prácticas en el Laboratorio de televisión, todos grabaron un texto informativo. A lo largo de la asignatura realizaron otras diez grabaciones de diferentes formatos. Al finalizar el curso grabaron de nuevo una noticia. La misma para todos. Inmediatamente antes de ambas grabaciones, los participantes respondieron a los siguientes cuestionarios:

- Cuestionario de dificultad de la tarea (Elaboración propia).

- Cuestionario de autoeficacia (Elaboración propia siguiendo el método recomendado por Bandura, 1997, de incorporar a la escala los comportamientos que los expertos en la materia de que se trate, en este caso, comunicación, consideren asociados con el máximo rendimiento, en este caso, la máxima eficacia comunicativa).

- Cuestionario de ansiedad -estado previo a la locución. Adaptado a partir del Inventario Revisado de Ansiedad-Estado Competitiva (Cox; Martens; Russell, 2003).

Después de ambas grabaciones, los participantes respondieron al siguiente cuestionario:

- Cuestionario de flujo (Jackson; Marsh, 1996). Versión española validada por García Calvo et al. (2008).

El último día de la asignatura, los alumnos respondieron de nuevo a los cuestionarios de confianza para hablar en público y confianza ante la locución, igual que hicieran el primer día de presentación. La calidad de grabaciones realizadas el primer y el último día fueron evaluadas por un panel de 10 expertos -profesores universitarios de Comunicación- que utilizaron un diferencial semántico con escalas de cinco puntos y los siguientes ítems: incómodo/a - natural; inseguro/a - seguro/a; distante - cercano/a; confuso/a - claro/a; no creíble - creíble. Por último, los alumnos escribieron un relato de su experiencia donde referían las mayores dificultades percibidas así como los facilitadores advertidos en su itinerario.

\section{3. - Resultados}

El análisis estadístico de las diferentes mediciones constató una mejoría general significativa del grupo en todas las variables analizadas: los participantes aumentaron la calidad de su locución, incrementaron su confianza general para ponerse delante de las cámaras y micrófonos, disminuyeron su nivel de ansiedad previa a las grabaciones y aumentaron su percepción de autoeficacia.

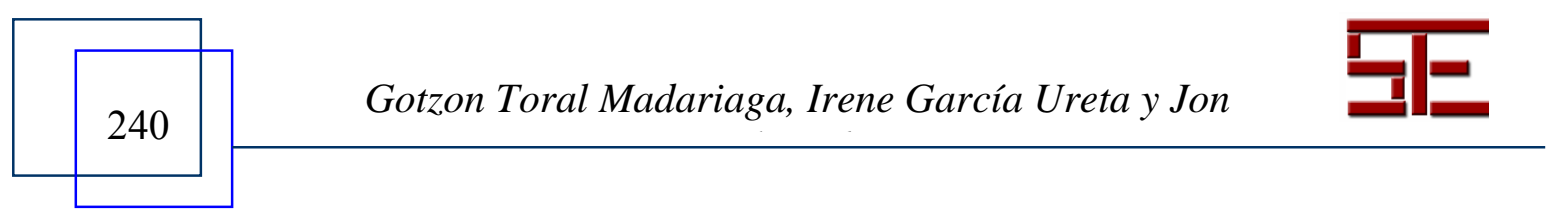




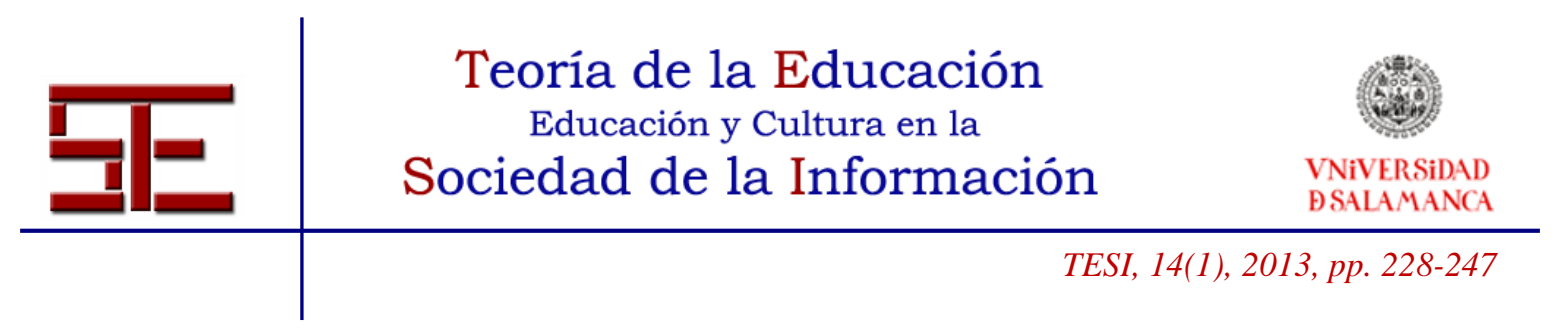

En la grabación final también percibieron las características de la experiencia de flujo en mayor medida que en la locución inicial. Los participantes advertían un mayor equilibrio entre la dificultad de la tarea y sus habilidades para afrontarla, experimentaban una mayor concentración, percibían sus objetivos con mayor claridad, tenían una mayor sensación de control, una disminución de la conciencia de sí mismos y, por consiguiente, la experiencia les resultaba más gratificante.

Además, quienes experimentaban un mayor nivel de flujo consiguieron una mayor calidad en la locución, a juicio del panel de expertos que evaluó la primera y la última grabación. Un análisis clúster, realizado con las puntuaciones otorgadas a los alumnos por este panel de expertos, permitió diferenciar dos perfiles, caracterizados por una mayor o menor calidad de la locución. Posteriormente, el contraste no paramétrico de MannWhitney dejó claro que ambos grupos se diferenciaban significativamente en el nivel de flujo experimentado, siendo dicho nivel superior en el grupo que obtenía una locución de mayor calidad.

Aunque las mediciones realizadas no han permitido establecer una correlación significativa, el análisis atento de sus Historias de vida evidencia que los participantes perciben una relación directa entre la nitidez de la visualización realizada previamente y la calidad de su grabación posterior. Y viceversa: un déficit en el ejercicio de visualización anticipaba un peor resultado. Como muestra, los testimonios siguientes:

- El ejercicio de imaginarnos cómo locutamos antes de hacerlo en radio me ayudó mucho, me imaginé haciéndolo correctamente, dominando el estrés y los nervios [...]

- A través de la visualización fui capaz no sólo de verme en esta situación, sino de desenvolverme en ella. Aunque los nervios me invadían, al poco rato de empezar a contar el monólogo hacia la cámara, me tranquilicé y me concentré en lo que estaba haciendo de tal forma que el tiempo que transcurrió mientras hablaba pasó rápidamente $[\ldots]$

- Fallé en esta última grabación, no era capaz de visualizarme haciendo un monólogo e iba con un "no puedo" en mente [...]

- Me he imaginado perdiendo el control de la situación, tal y como ha sucedido [...]

En sus relatos, los participantes relacionan la eficacia en la visualización con las diferentes modalidades de exposición expandida a la tarea. Tal y como se puede observar en la Tabla III, contemplar a gusto una actividad, imaginarse realizándola y llevarla a cabo en las mejores condiciones posibles son experiencias complementarias en un proceso natural de aproximación y aprendizaje.

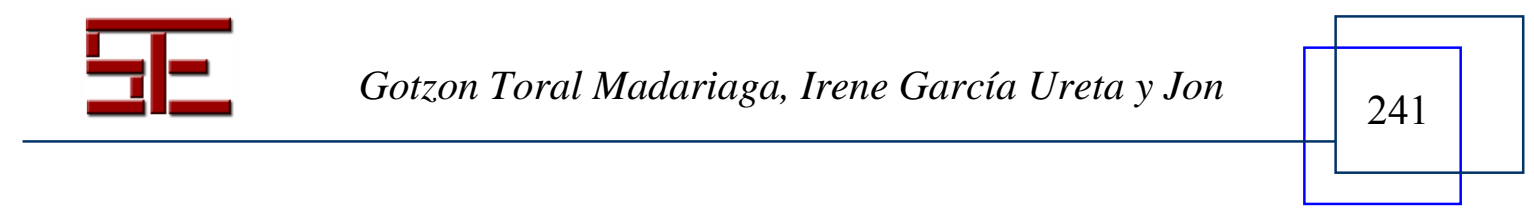



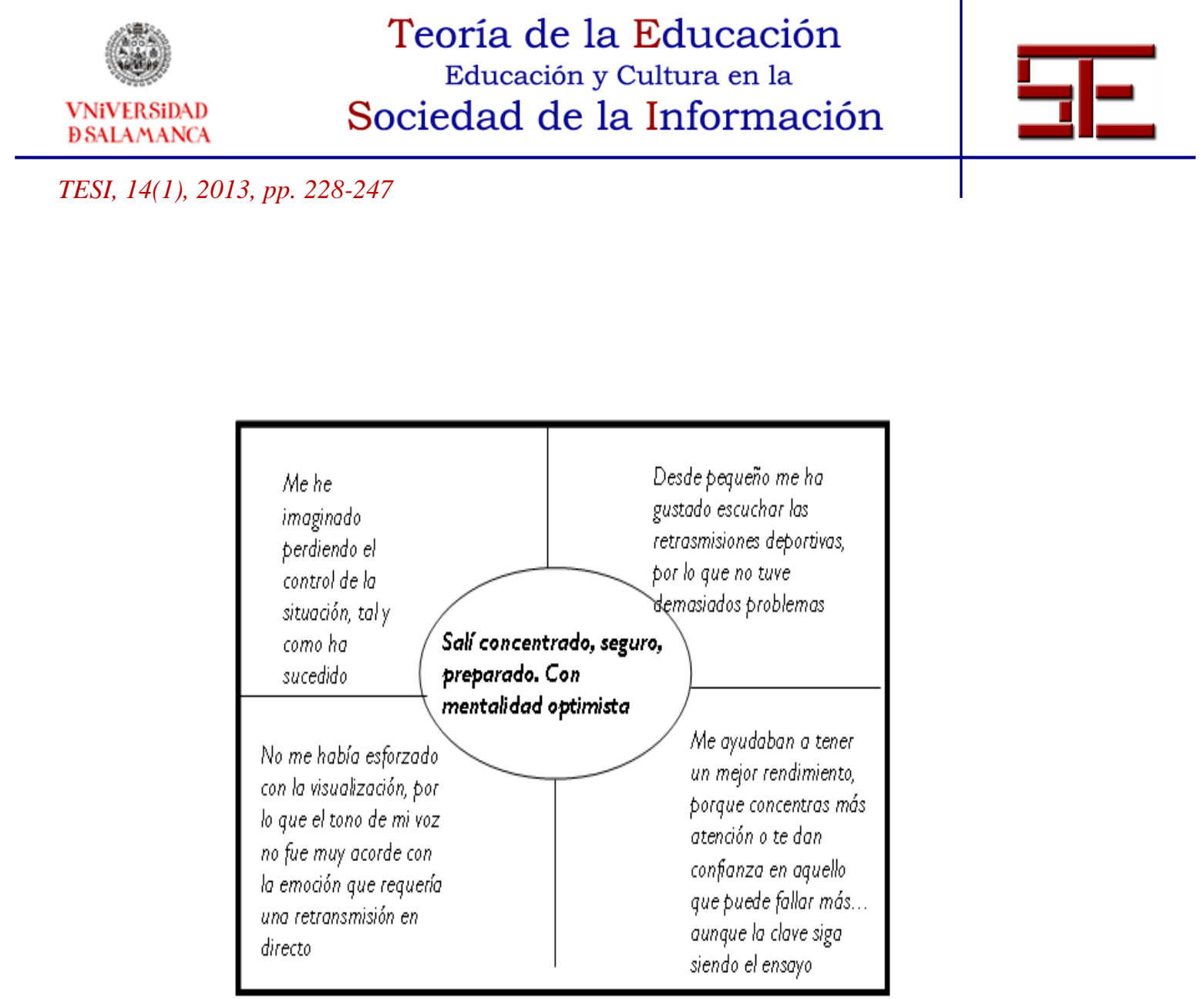

Fig. III. Eficacia percibida por los sujetos en una aproximación que identifica todos los procedimientos de Exposición a la tarea, y centra su atención en la Exposición imaginada o Visualización

- Considero que para realizar un monólogo delante de una cámara hay que tener cierta gracia que no se consigue sólo con las técnicas para una buena presentación. Y es por eso que fallé en esta última grabación, no era capaz de visualizarme haciendo un monólogo e iba con un "no puedo" en mente [...].

- Para visualizar mejor cómo iba a hacer el número humorístico, me dediqué a ver a algunos maestros $[\ldots]$

- Creo que en general las visualizaciones eran positivas y me ayudaban a tener un mejor rendimiento, bien porque concentras más atención o porque te dan confianza en aquellos puntos que te puede fallar más. A mí personalmente sí me predisponían a hacerlo bien, aunque la clave siga siendo el ensayo [...]

La exposición expandida a la tarea, junto con el refuerzo positivo de profesores y participantes, se considera eficaz para disolver la aprensión comunicativa asociada a la evaluación de los demás en una situación extraña, alimentando la autoconfianza de los participantes, su concentración y desenvoltura.

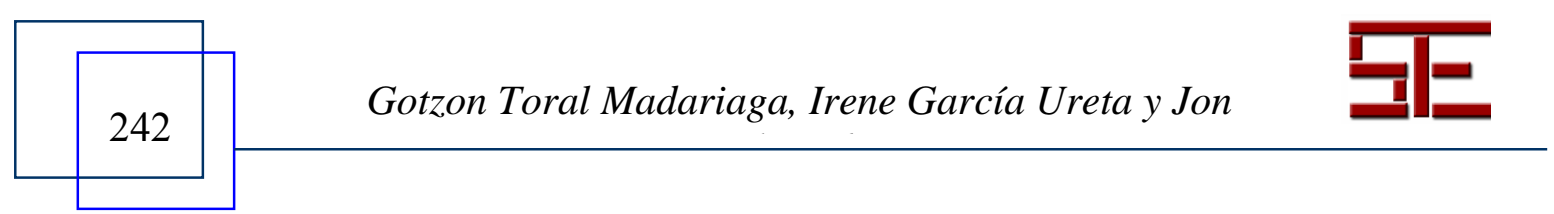




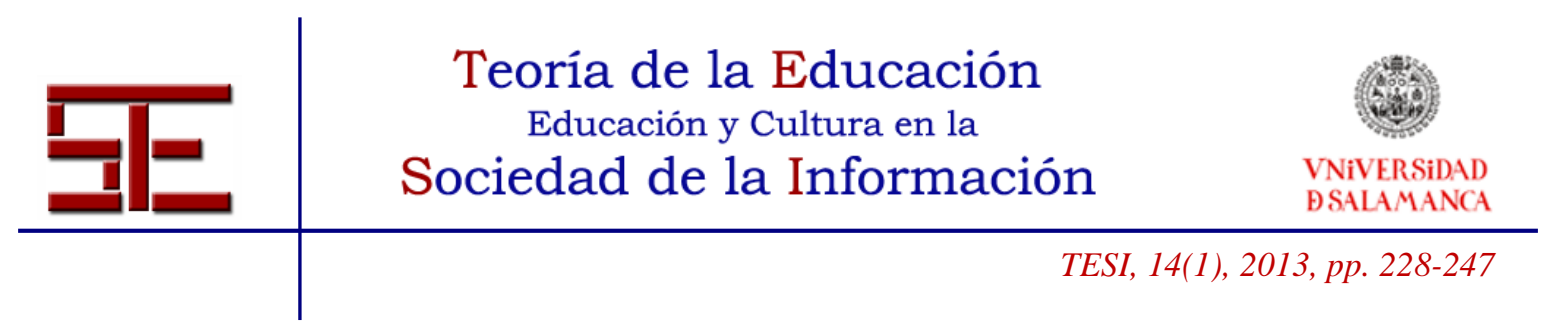

Exposición Sí Exposición No

\begin{tabular}{|l|l|l|}
\hline Escenario & Familiar & Desconocido \\
\hline Tarea & Clara & Confusa \\
\hline Público & Amistoso & Extraño \\
\hline
\end{tabular}

Figura IV Exposición y Autoconfianza percibida

- He visualizado un plató vacío en el que me sentía muy cómoda [...]

- Cada semana he ido sintiendo más confianza con la gente de clase, y la vergüenza iba menguando [...]

- No quería dejar sin valorar la aportación de todos a la mejora. No se puede decir que a nadie le haya faltado una palabra de aliento o un aplauso. Eso aunque sea a pequeña escala, es esencial. El sentirse respaldado, animado y reconocido, ha creado el clima idóneo para que la gente mejore [...].

\section{4. - Conclusiones}

De los resultados obtenidos en las mediciones de encuestas y en los relatos de los participantes se desprende la eficacia de un proyecto formativo que actúa como catalizador de su biología comunicativa. Junto a su satisfacción, los participantes han reclamado una mayor duración, subrayando las limitaciones de un programa docente optativo y cuatrimestral.

La falta de práctica social, acentuada por el temor a exponerse en público -mayor en televisión que en radio- interfiere en la expresión del potencial comunicativo de los individuos. Nuestra estrategia formativa es novedosa porque prepara a un tiempo sus habilidades comunicativas y sus recursos emocionales para desenvolverse en el nuevo escenario de proximidad, básicamente emocional, que hoy domina la comunicación pública.

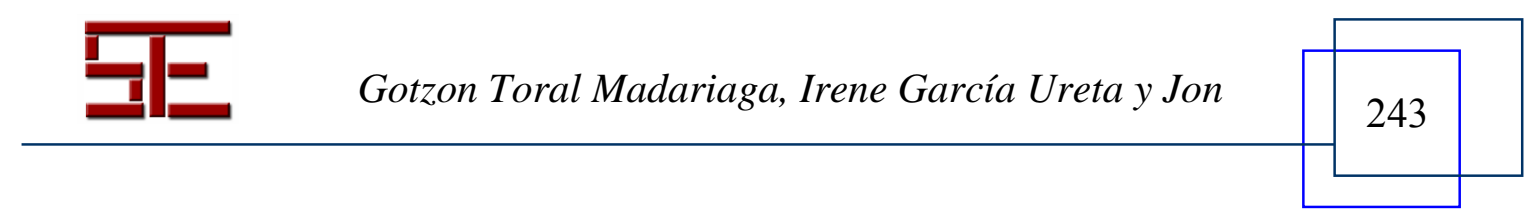




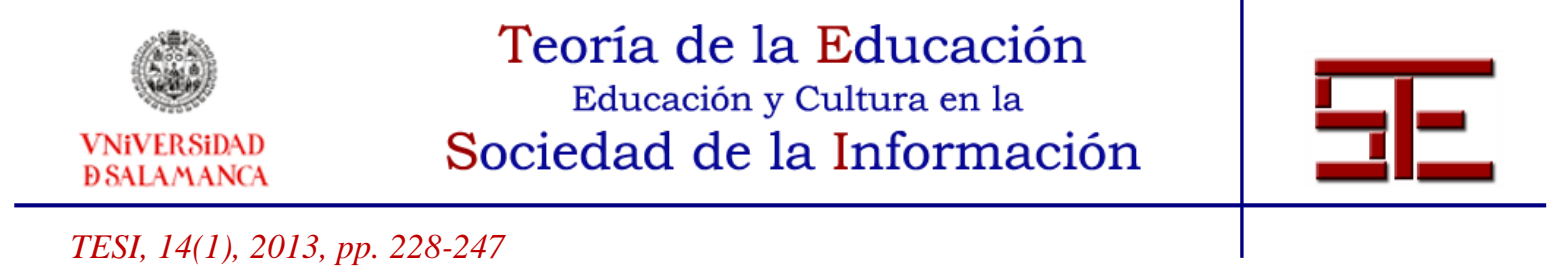

El disfrute de un reto equilibrado y atractivo convalida el interés de este modelo de flujo para disolver la aprensión comunicativa, adquirir la confianza necesaria, motivar el aprendizaje y mejorar la calidad de la comunicación en una situación típicamente estresante, que también experimentan los profesionales examinados diariamente por los índices de audiencia.

En sus relatos, los participantes han percibido que la calidad de la práctica de visualización previa a las grabaciones anticipaba la posterior calidad de sus producciones. Sin embargo, no ha sido posible establecer esta misma correlación a partir del análisis de datos procedentes de las escalas que ellos mismos rellenaron antes y después de cada práctica. Sucesivas investigaciones con mayor número de participantes debieran contrastar la eficacia predictiva de esta práctica de visualización, también a través de metodologías cuantitativas.

Consideramos que saber, querer y poder interactuar con más autonomía y de forma más resonante en el nuevo espacio global de los medios contribuye a empoderar a profesionales y usuarios para un ejercicio más pleno de su nueva ciudadanía digital. Entendemos que este desarrollo de la interactividad es de interés general para fertilizar la comunicación pública, favoreciendo un mayor equilibrio en el intercambio de flujos comunicativos, en lugar de abandonarlos a los intereses particulares de los más poderosos consorcios mundiales y de sus comunicadores más carismáticos.

\section{5. -Bibliografía}

Aristóteles (1971). La Retórica. Madrid: Instituto de Estudios Públicos.

Ayres, J. (1997). A component theory of communication apprehension. Ruston, WA: Communication Ventures.

Bados, A. (2008). Miedo a hablar en público. Repositorio digital de la Universidad de Barcelona. Disponible en http://diposit.ub.edu/dspace/bitstream/2445/6323/1/MHP.pdf

Bandura, A. (1997). Self-efficacy: The exercise of control. New York: W.H. Freeman.

Blakemore, S.-J., Decety, J. (2001). From the perception of action to the understanding of intention. Nature Reviews: Neuroscience, 2 , 561-567.

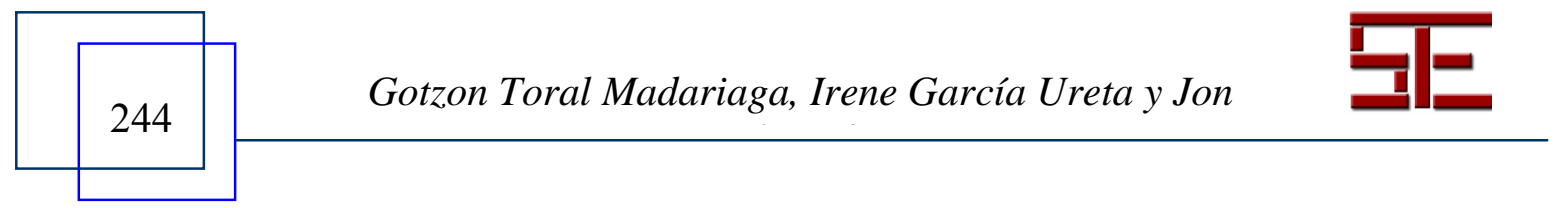




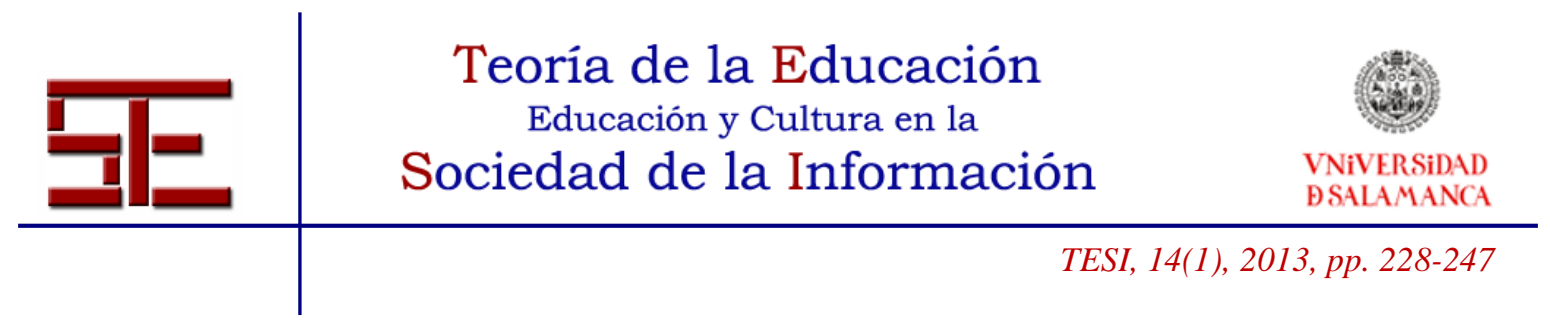

Castells, M. (2009). Communication Power. New York: Oxford University Press.

Cea, J. I.; Reyes del Paso, G. (2005). Effects of a brief respiratory training on baroreceptor cardiac reflex power and effectiveness. Applied Psychophysiology and Biofeedback, 30 (4).

Cox, R. H., Martens, M. P. \& Russell, W. D. (2003). Measuring anxiety in athletics: The Revised Competitive State Anxiety Inventory-2. Journal of Sport and Exercise Psychology, 25, 519-533.

Csikszentmihalyi, M. (1990). Flow: The psychology of optimal experience. New York: Harper \& Row.

Furmark, T., Tilfors, M., Everz, P.O. (1999). Social Phobia in the general population: Prevalence and sociodemographic profile. Social Psychiatry and Psychiatric Epidemiology, 38, 416-424.

García Calvo, T., Jiménez, R., Santos-Rosa, F. J., Reina, R., Cervelló, E. (2008). Psychometric Properties of the Spanish Version of the Flow State Scale. The Spanish Journal of Psychology, 11(2): 660-669.

Gatchel, R. J., Proctor, J. D. (1976). Effectiveness of voluntary heart rate control in reducing speech anxiety. Journal of Consulting and Clinical Psychology, 44 (3), 381389.

Goleman, D. (2011). El cerebro y la inteligencia emocional. Barcelona: Eds. B.

Goleman, D. y Boyarzis, R. (2002). El líder resonante crea más. Barcelona: Plaza y Janés. Hall, C., Mack, D., Paivio, A., Hausenblas, H. (1998). Imagery use by athletes: Development of the Sport Imagery Questionnaire. International Journal of Sport Psychology, 29, 73-89.

Hook, J. N., Smith, C. A. \& Valentiner, D. P. (2008). A short-form of the Personal Report of Confidence as a Speaker. Personality and Individual Differences, 44, 1306-1313.

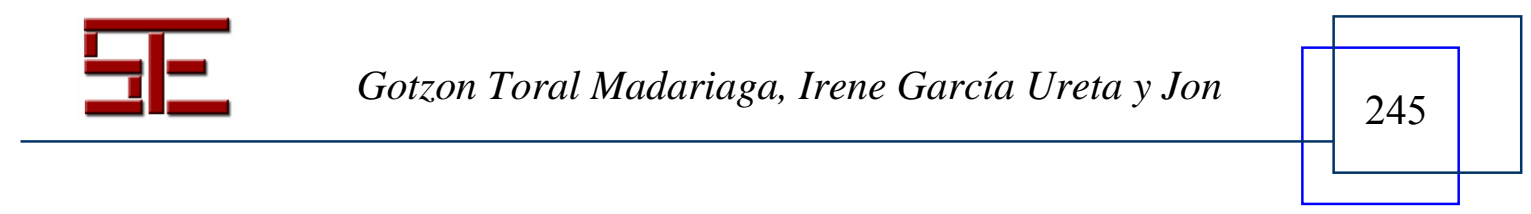




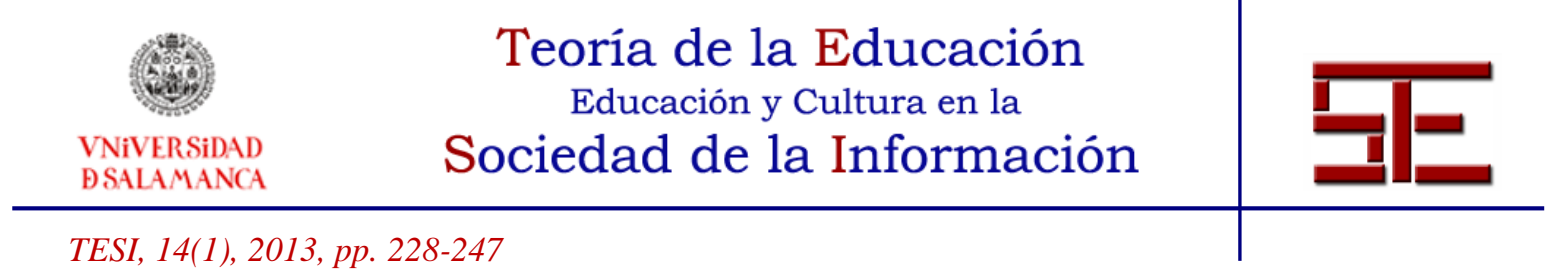

Iacoboni, M. (2009). Las Neuronas Espejo. Buenos Aires: Katz.

Legerón, P. y André, Ch. (1997). El miedo a los demás. Bilbao: Eds. Mensajero.

McCroskey, J. C. (1984a). The communication apprehension perspective. In Daly, J.A. and J. C. McCroskey (Eds). Avoiding Communication. Beverly Hills: Sage Publications.

McCroskey, J. C. (2009). Communication Apprehension: What We Have Learned in the Last Four Decades. Human Communication, 12 (2), 157-171.

Petrides, K. V. (2011). Ability and Trait Emotional Intelligence. En Chamorro-Premuzic, T., von Stumm, S. and Furnham, A (Eds.). The Wiley-Blackwell Handbook of Individual Differences, Blackwell Publishing.

Rizzolatti, G. y Craighero, L. (2004). The Mirror neuron System. Annual Review of Neuroscience. 27 (1), 169-192.

Rosenthal, R. Y Tickle-Degnan, L. (1990) The Nature of Rapport and Its Nonverbal Correlates en Psychological Inquiry, 1, $\mathrm{n}^{\circ} 4,285-293$.

Schmidt, N. L. (2006). "Administered tactile therapy: A proposed intervention for the treatment of public speaking apprehension". Thesis ( $\mathrm{Ph}$. D.). Washington State University. Available at https://research.wsulibs.wsu.edu:8443/dspace/bitstream/2376/484/1/n_schmidt_050306. pdf.

Thomas, C. (2005). Conquering Speech Anxiety. Supplemental chapter for P.E. Nelson and J.C. Pearson (Eds.) "Confidence in Public Speaking (Telecourse version)" ${ }^{\text {th }}$ Ed. Roxbury Publishing Company. Available at http://roxbury.net/images/pdfs/cps6chape.pdf

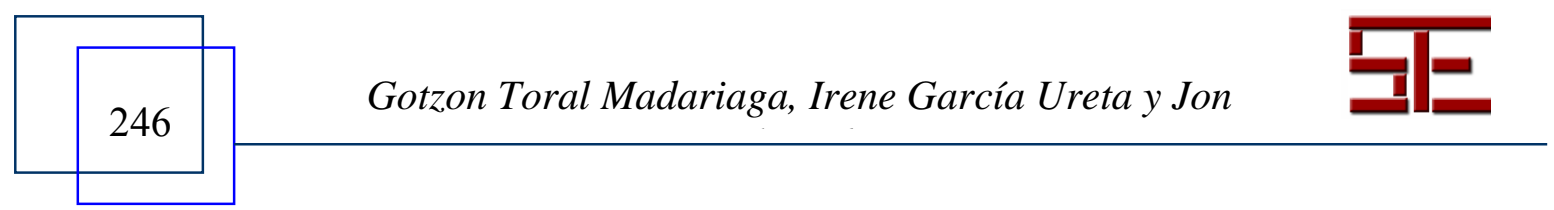




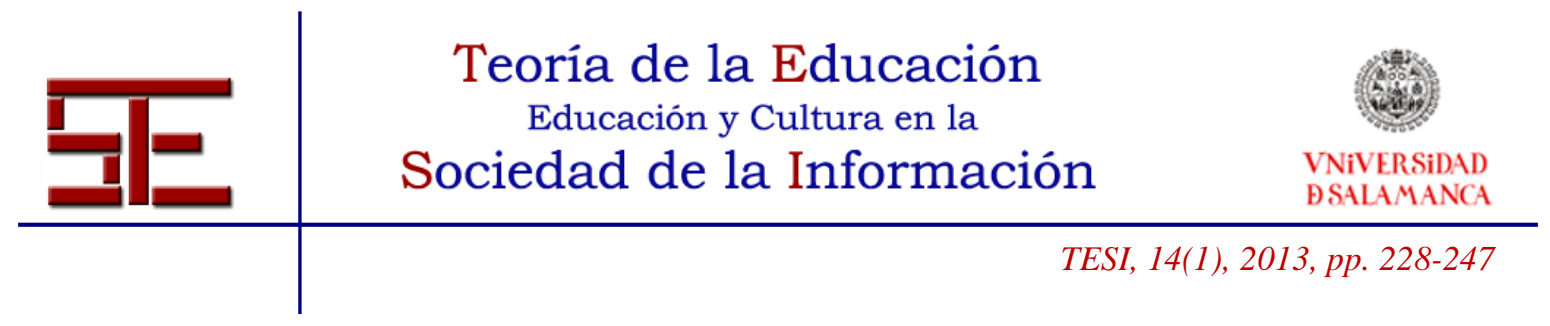

Watzlawizck, P. Beavin, J. y Jackson, D. (1981). Teoría de la comunicación humana. Barcelona: Herder.

Para citar el presente artículo puede utilizar la siguiente referencia:

Toral Madariaga, G., García Ureta, I. y Murelaja Ibarra, J. (2013). La preparación de comunicadores resonantes. De las redes neuronales a la sociedad red. Revista Teoría de la Educación: Educación y Cultura en la Sociedad de la Información. 14(1), 228-247 [Fecha de consulta: dd/mm/aaaa].

http://campus.usal.es/ revistas_trabajo/index.php/revistatesi/article/view/9450/9739

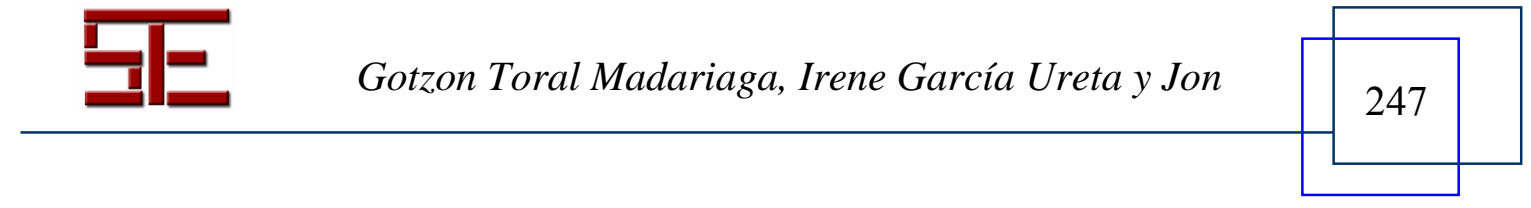

